\title{
Participating in Social Network Online Purchase: How Significant Emotional Intelligence IS
}

\author{
Sri Fatiany Abdul Kader Jailani, Abdul Kadir Othman and Erne Suzila Kassim
}

Faculty of Business Management, Universiti Teknologi MARA, 42300 Puncak Alam, Malaysia,

Correspondence should be addressed to: Sri Fatiany Abdul Kader Jailani

fatiany@puncakalam.uitm.edu.my

Received date: 13 May 2013; Accepted date: 19 August 2013; Published date: 31 January 2014

Copyright (c) 2014. Sri Fatiany Abdul Kader Jailani, Abdul Kadir Othman and Erne Suzila Kassim. Distributed under Creative Commons CC-BY 3.0

\begin{abstract}
The social networking has become a phenomenon not only to the social system, but also to the business activities. Engaging the social network for buying and selling products and services has become common, although these shopping sites are lacking of many trustworthy elements due to their limited virtual characteristics. Thus, it motivates us to examine the role of emotional intelligence, trust and perceived value as significant psychological elements in predicting consumers' decisions to engage in social networking online purchase. We then proposed a model that links relationships of emotional intelligence, trust, perceived value, purchased intention and confirmation. Using a survey conducted via a cross sectional study, we collected data from 334 respondents who have taken part in social networking online purchase. Based on the regression analyses, the findings reveal that consumers' decisions are explained by emotional intelligence and trust. Besides, trust plays the role as a predictor for perceived value and purchase intention. In addition, there are also significant relationships between perceived value and purchase intention, and between purchase intention and confirmation. The study contributes to the understanding of emotional intelligence as the basis for online and mobile retailers in taking the appropriate strategies to attract more consumers and generate higher sales. Building on this research and for knowledge enrichment, future study may incorporate social informatics in building social intelligence of the future social business community.
\end{abstract}

Keywords: Emotional intelligence, trust, social networking online purchase

\section{Introduction}

Purchasing products and services via the Internet has been part of the social lifestyle for many people. The online shopping is also known as e-shopping, Internet shopping, web shopping, online store, online retail and virtual shopping. Amazon.com and e-Bay are among the pioneers and still continuing to be the largest online shops in terms of market

Cite this Article as: Sri Fatiany Abdul Kader Jailani, Abdul Kadir Othman and Erne Suzila Kassim (2014),

"Participating in Social Network Online Purchase: How Significant Emotional Intelligence IS," Journal of Internet and e-Business Studies, Vol. 2014 (2014), Article ID 460262, DOI: 10.5171/2014. 460262. 
shares. The vast evolvement of the information and communication technology does not only offer many possibilities to online purchase, but also enhances the trend in online purchase. In this instance, utilizing social network for offering, selling and buying goods and services has become common, especially to the young generations. Unlike in the previous years, consumers now have become more receptive and are willing to engage in the social networking online shopping despite the fact these shopping sites are lacking of many trustworthy elements due to their limited virtual characteristics.

Therefore, the consumers' decision to participate and utilize the social commerce agents is very appealing to be explored. This is because taking part in online shopping via the social networking sites involves the willingness to take risks and uncertainties. Many factors are expected to contribute in explaining consumers' decision in consumption situations. In many situations, emotions play a great role in explaining how people act and make judgment (Kidwell, Hardesty \& Childers, 2008). Kidwell et al., (2008) further added that understanding the emotional processing capabilities may have important effects on consumer outcomes. In addition, risk and trust are two interrelated facets of decision making that explain how people choose to act (Josang \& Presti, 2004). Recognizing the importance of these two antecedents, this study is intended to examine the role of emotional intelligence and trust as significant psychological elements in predicting the consumers' decisions to engage in social networking online purchase, which has not been extensively studied in the recent years.

\section{Review of Literature}

\section{Emotional Intelligence and Trust}

Emotional intelligence (EI) is a popular concept that has attracted a number of researchers from various fields including psychology, sociology, education, hospitality, health, business and even engineering. Because of its popularity, there are various conceptual definitions that have been highlighted by different authors in making it relevant to their respective fields of study. Principally, EI concept can be categorized into three streams; traits model, ability model and the mixed model. For the purpose of this study, EI is seen as the ability model as it is meant to capture the individual's ability to address emotional issues that are related to online purchasing behavior. EI has been defined as the ability to perceive accurately, appraise, and express emotion; the ability to access and/or generate feelings when they facilitate thought; the ability to understand emotion and emotional knowledge; and the ability to regulate emotions to promote emotional and intellectual growth (Mayer \& Salovey, 1997).

Wong and Law (2002) have refined the concept by suggesting four dimensions of EI that is reliably used across settings and contexts. The four dimensions are selfemotional appraisal (SEA), others emotional appraisal (OEA), regulation of emotion (ROE) and use of emotion (UOE). SEA relates to the individuals' ability to understand their deep emotions and be able to express these emotions naturally, OEA reflects peoples' ability to perceive and understand the emotions of those people around them, ROE concerns the ability of people to regulate their emotions, which will enable a more rapid recovery from psychological distress, and UOE deals with the ability of individuals to make use of their emotions by directing them towards constructive activities and personal performance. Since the focus of the present study is on the online purchasing behavior, one dimension of $\mathrm{EI}$; others emotional appraisal, is excluded due to its relevancy.

Trust is also a concept which has been defined differently by various researchers. A universal definition of trust is that it reflects a confidence of a party that another party is reliable (Morgan \& Hunt, 1994) and that the parties concerned will act with a level of integrity when interacting with each other 
(O’Malley \& Tynan, 1997). Trust basically includes three major components; credible, integrity and benevolent components (Heffernan, O’Neill, Travaglione \& Droulers, 2008). Credible component concerns the capability of the other party to undertake the purpose of the partnership. Integrity component reflects the adherence of the other party to written or verbal promises. Benevolent component relates to capability of the other party to accommodate and act with equity when new conditions relating to the relationship arise.

Trust is the emotional basis that forms the cooperation as asserted by Dunn (1990), "confident expectation of the benign intentions" of others. In the context of online purchasing, trust is the most critical aspect that needs to be initiated nurtured and enhanced. In contrast to traditional concept of business, trust in online purchasing is more critical that requires special attention. There is where business owner or retailer is required to address the emotional aspects of the buyers so that customer trust emerges and forms the basis of the decision to purchase (Kidwell et al., 2008).

The first component of customer EI is selfemotional appraisal. When customers are aware of their emotional states, they tend to make decision accordingly; positive emotions lead to favorable decision whereas negative emotion entails undesirable decision (Kidwell et al., 2008) due to the trust level. Normally, trust is high when an individual is experiencing positive emotions and vice versa. The second component of $E I$ is the regulation of emotion, which refers to the ability of individuals to effectively manage their emotion to be in the positive emotional states. Customers' emotions can change from one state to another when they experience certain events, especially astonishing or shocking events. The ability to recover from these events helps the customers to trust the business owner as trust exists when the customers are able to engage in rational thinking (Kidwell et al., 2008).
The last component of EI is the use of emotion. When the customers become rational, they will engage in weighing the benefits resulting from the transaction, the credibility and integrity of the business owner in pursuing the relationship. If the customers 'feel' positively about the relationship, most probably the relationship will be successful and the customers will participate in online purchasing (Kidwell et al., 2008). This situation requires business owner to devise ways and means in ensuring that the emotions of the online purchasers are always positive and they engage in positive thinking so that trust can be cultivated that can lead to online purchasing behavior.

\section{Trust, Purchase Intention and Perceived Value}

Customer purchase intention is an area that is widely discussed in the literature. Customer online purchase intention in the web-shopping environment will determine the strength of a consumer's intention to carry out a specified purchasing behavior via the Internet (Salisbury, Pearson \& Miller, 2001). According to Tan and Guo (2005), the internet is viewed by customer as a world of chaos. As pointed by Sonja (2002), trust plays a crucial role in the development of electronic business and some relevant factors in the emergence of trust problems in on transactions should be therefore analyzed. Purchase intention is one of the components of consumer cognitive behavior on how an individual intends to buy a special brand (Kwek, Tan \& Lau, 2010).

In addressing the customer purchase intention, Dodds and Monroe (1985) have proposed a model illustrating the relationships among price, quality and perceived value. In that model, they mentioned that perceived value is an important factor in consumers' purchasing decision process, and consumer will buy a product with high perceived value. Similarly, Chong, Yang and Wong (2003) proposed the relationships among trust, perceived value and purchase intention, where customer trust will significantly lead to perceived value 
and subsequently perceived value will affect purchase intention. It is consistent with Thaler (1985) who also considered that perceived value is an important antecedent of consumers purchase intention because it is the composition of transaction and acquisition utilities.

Bhattacherjee (2001) proposed and tested the expectation-confirmation theory of consumer purchasing behavior found that users' continuance intention is determined by their satisfaction with IS use and perceived usefulness of continued IS use. User satisfaction, in turn, is influenced by their confirmation of expectation from prior IS use and perceived usefulness. In this paper, confirmation is regarded as the result of purchase intention since consumers might have the intention to purchase prior to purchase confirmation. Similarly, consumers might have positive perceived value before they develop purchase intention. Based on the above discussion, we propose the following hypotheses:
H1: Emotional intelligence has a relationship with trust.

H2: Trust has a relationship with perceived value.

H3: Trust has a relationship with purchase intention.

H4: Perceived value has a relationship with purchase intention.

H5: Purchase intention has a relationship with confirmation.

The conceptual model is depicted in Figure 1

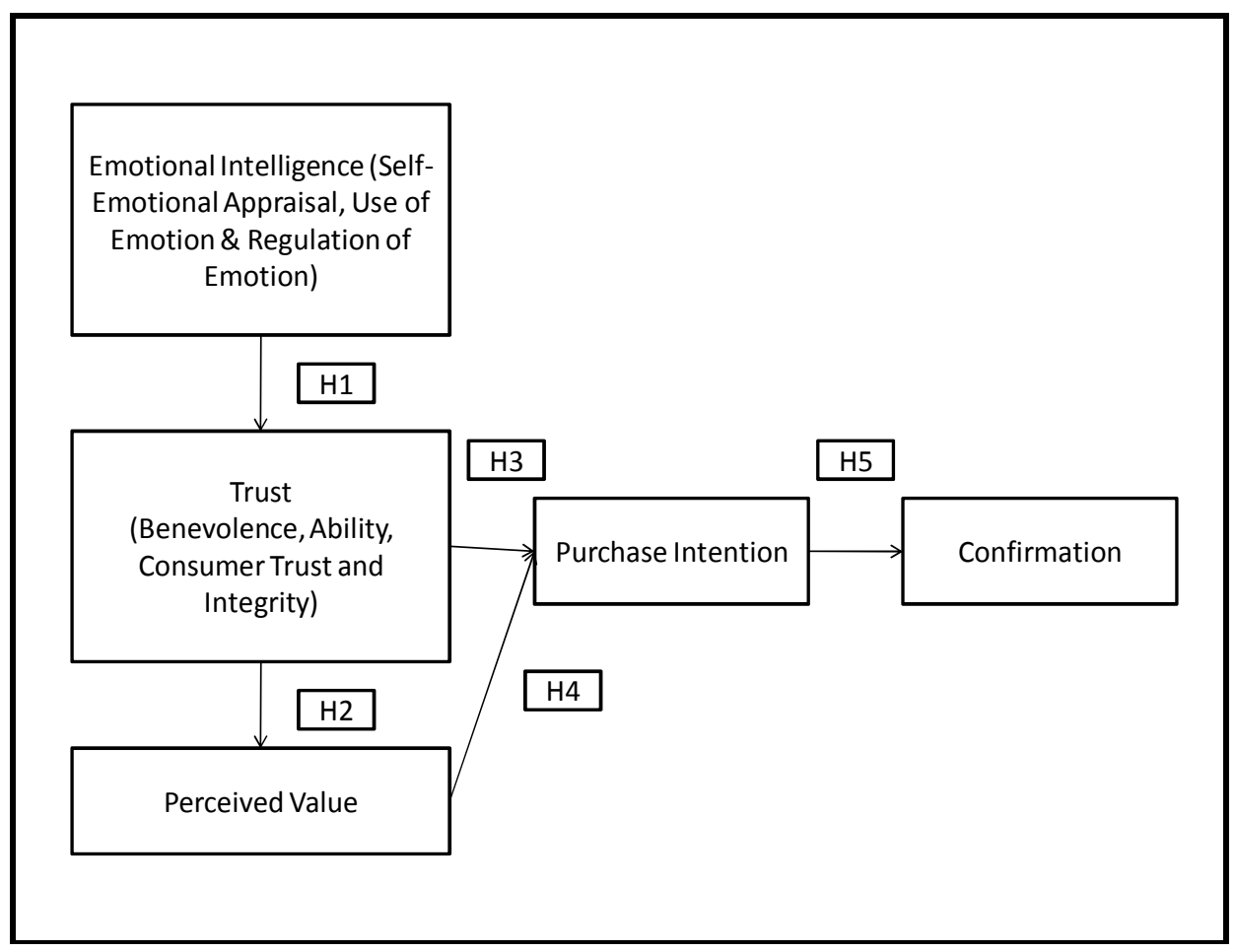

Figure 1: The Conceptual Framework of the Study that Addressing the Relationships among the Studied Variables 


\section{Research Methodology}

\section{Instrument Construction}

The research instrument used in the present study was developed based on items that had been used and tested in the previous studies. In order to make it appropriate for the context of the study, the items were slighted amended. The items for trust, perceived value and purchase intention were applied using a 5-point Likert scale, ranging from 1 as strongly disagree to 5 as strongly agree. The entire questions were adapted from Gefen, Karahanna and Straub (2003), Benbasat and Wang (2005), Sirdeshmukh, Singh and Sabol (2002) and Dodds and Monroe (1991). Confirmation on the use of blogs to purchase goods and repeat purchase were measured by using items adopted from Bhattacherjee (2001).

Before the actual survey was conducted, a face and content validity of the instrument were verified. The questionnaire was pretested by academic staff and graduate students in the area of information system and e-commerce. They were asked to critically evaluate the questionnaire with regard to the objectives, contents, clarity and ease of completion. In addition, a pilot study was conducted to determine the reliability of the instrument. A total of 30 respondents took part in the study. The results of reliability analysis indicate that items measuring each construct in the questionnaire have high Cronbach's alpha values of more than 0.75 , indicating that the questionnaire is reliable and can be used for the study.

\section{Data Collection}

The population of the study comprised those who had involved in the purchasing activities through the social networking sites. The sample of the study was chosen using simple random sampling. A total of 450 sets of questionnaire were distributed and 334 responses were returned, yielding a response rate of $74.2 \%$. The study used perceptual measures to capture data as these are acceptable measures in most survey research. Table 1 summarizes the profile of the respondents.

\section{Table 1: Profile of the Respondents}

\begin{tabular}{|l|l|l|l|}
\hline Measure & Items & Frequency & Percent \\
\hline Gender & Male & 107 & 32.0 \\
\cline { 2 - 4 } & Female & 227 & 68.0 \\
\hline \multirow{4}{*}{ Age } & Less than 21 years old & 37 & 11.1 \\
\cline { 2 - 4 } & $21-30$ years old & 188 & 56.3 \\
\cline { 2 - 4 } & $31-40$ years old & 73 & 21.9 \\
\cline { 2 - 4 } & $41-50$ years old & 26 & 7.8 \\
\cline { 2 - 4 } & More than 50 years old & 10 & 3.0 \\
\hline \multirow{4}{*}{ Qualighest Academication } & Secondary School & 19 & 5.7 \\
\cline { 2 - 4 } & 'A' Level & 26 & 7.8 \\
\cline { 2 - 4 } & Professional Certificate & 22 & 6.6 \\
\cline { 2 - 4 } & Diploma & 115 & 34.4 \\
\cline { 2 - 4 } & Bachelor's Degree & 116 & 2.4 \\
\cline { 2 - 4 } & Professional Degree & 8 & 8.4 \\
\cline { 2 - 4 } & Master Degree & 28 & \\
\hline
\end{tabular}




\begin{tabular}{|l|l|l|l|}
\hline Measure & Items & Frequency & Percent \\
\hline \multirow{5}{*}{ Occupation } & Student & 122 & 36.5 \\
\cline { 2 - 4 } & Public Sector Employee & 79 & 23.7 \\
\cline { 2 - 4 } & Private Sector Employee & 122 & 36.5 \\
\cline { 2 - 4 } & Self-Employed & 2 & 0.6 \\
\cline { 2 - 4 } & Unemployed & 7 & 2.1 \\
\hline Total Years of & Less than 1 year & 9 & 2.7 \\
\cline { 2 - 4 } Internet Usage & 1-5 years & 88 & 26.3 \\
& 6-10 years & 141 & 42.2 \\
& More than 10 years & 96 & 28.7 \\
& & & \\
\hline
\end{tabular}

\section{Factor Analysis}

Prior to the hypothesis testing, an exploratory factor analysis was performed to reduce sets of variables using the principal axis factoring and Varimax with Kaiser Normalization rotation to ascertain that trust, perceived value, purchase intention, confirmation and emotional intelligence were distinct constructs. The KMO values of 0.929 and 0.854 indicated that factor analysis was appropriate, the MSA values of more than 0.5 suggested that all variables should be included in the factor analysis, and the Bartlett's test is significant, implying the variables were correlated. The results produced a total variance of $61.32 \%$ for trust, perceived value, purchase intention and confirmation. Meanwhile, the total variance of $63.04 \%$ was produced for emotional intelligence. All items measuring trust, perceived value, purchase intention and emotional intelligence measuring loaded under their respective factors as predicted.

\section{Results and Discussion}

A reliability test was conducted to measure the consistency of the items in measuring the intended variables. Cronbach's alpha was used to measure the internal consistency of trust, emotional intelligence, perceive value, purchase intention and confirmation. The data were then descriptively analyzed and the results are shown in Table 2. Based on the results, all items were reliable and measured what they were supposed to measure. In addition, the mean score for all items denotes that all respondents have a good level of agreement on each measure. Comparing all items, emotional intelligence (mean $=4.00)$, trust on the online system that specifies on system integrity (mean = 3.79 ), and perceived value (mean $=3.75$ ) produced the highest mean scores. On the other hand, general trust from the consumer produced the lowest mean score of 3.41 .

Table 2: Descriptive and reliability analyses

\begin{tabular}{|l|c|c|c|}
\hline \multicolumn{1}{|c|}{ Variable } & $\begin{array}{c}\text { Items } \\
\text { in scale }\end{array}$ & Mean & $\begin{array}{c}\text { Cronbach } \\
\text { alpha }\end{array}$ \\
\hline Trust & 4 & 3.41 & .820 \\
\hline Emotional Intelligence & 11 & 4.00 & .857 \\
\hline Perceived Value & 4 & 3.75 & .832 \\
\hline Purchase Intention & 4 & 3.71 & .842 \\
\hline Confirmation & 6 & 3.72 & .856 \\
\hline
\end{tabular}


Prior to multivariate data analysis, the data were tested to ensure that they are normally distributed, the relationship between the independent and dependent variables is linear and the error variance is homogeneous. Besides, the dependency of the variables and the interrelationships among the independent variables were also tested during the regression analysis. All assumptions for multivariate data analysis were met and the data were submitted for the intended analysis based on the objectives of the study. Subsequently, the data were tested for the association between variables, and the results are shown in Table 3 . The association between perceived value and purchase intention generates the strongest and significant result $(\mathrm{r}=.705 ; \mathrm{p}<.01)$, followed by the relationship between purchase intention and confirmation ( $\mathrm{r}$ $=.655 ; \mathrm{p}<.01)$. On the other hand, the link between emotional intelligence and purchase intention produces the least correlation even though it is still significant $(r=.350 ; \mathrm{p}<.01)$.

Table 3: Correlation Analysis

\begin{tabular}{|c|l|r|r|r|c|}
\hline No & & 1 & 2 & 3 & 4 \\
\hline 1 & Emotional Intelligence & & & & \\
\hline 2 & Trust & $.384^{* *}$ & & & \\
\hline 3 & Perceived Value & $.423^{* *}$ & $.637^{* *}$ & & \\
\hline 4 & Purchase Intention & $.326^{* *}$ & $.635^{* *}$ & $.705^{* *}$ & \\
\hline 5 & Confirmation & $.350^{* *}$ & $.619^{* *}$ & $.639^{* *}$ & $.655^{* *}$ \\
\hline **. Correlation is significant at the 0.01 level (2-tailed). \\
\hline
\end{tabular}

Finally, for the hypothesis testing, a series of regression analysis were conducted to examine the relationships between the variables. The results are depicted in Table 4 . The results of the analyses denote that emotional intelligence predicts the level of trust of the consumers on the social networking online purchase $(\beta=.387 ; \mathrm{p}$ $<.01)$. It explains $14.7 \%$ of the trust variance. Trust plays a role in the value perception of purchasing goods and services from the sites $(\beta=.637 ; p<.01)$, in which $40.5 \%$ of the perceived value is explained by trust. In addition, both trust $(\beta=635 ; \mathrm{p}<.01)$ and perceived value $(\beta=.705 ; p<.01)$ influence purchase intention with the explanation of variance of $40.3 \%$. Finally, confirmation is explained by purchase intention $(\beta=.655$; $p$ $<.01)$. All hypotheses were supported.

Table 4: Summary of Hypotheses

\begin{tabular}{|l|l|c|c|c|}
\hline Hypothesis & \multicolumn{1}{|c|}{ Relationship } & $\boldsymbol{\beta}$ & Sig. & Result \\
\hline H1 & Emotional Intelligent and Trust & .387 & .000 & Supported \\
\hline H2 & Trust and Perceived Value & .637 & .000 & Supported \\
\hline H3 & Trust and Purchase Intention & .635 & .000 & Supported \\
\hline H4 & Perceived Value and Purchase Intention & .705 & .000 & Supported \\
\hline H5 & Purchase Intention and Confirmation & .655 & .000 & Supported \\
\hline
\end{tabular}




\section{Conclusion}

This study examines the role that emotional intelligence, trust and perceived values as the psychological elements in predicting consumers' behavior towards purchasinggoods and services via the social networking sites. Although emotional intelligence explains the behaviour, its influence is weak.

However, there seems to be an acceptance in the trend of utilizing the social networking as shopping sites. This is reflected in the perception of the value gained, the intention to use and the actual conduct of the behaviour. The findings are consistent with those found by Hassan et al., (2012), Kidwell et al., (2008) and Kwek et al., (2010) where consumers' trust is important to influence their perceived value and purchase intention. Subsequently, purchase intention will determine the confirmation of purchase by the consumers.

The findings of the present study serve as a guideline for mobile retailers or social network online sellers to improve their websites, purchasing process as well as the quality of delivery systems as these elements form the basis for the consumers to judge where the retailer can be trusted or otherwise. Besides, the online retailers are suggested to know and work within their customers' emotional states as trust and perceived value are developed based on the positive emotional states of the consumers. By empathizing with the emotions of the consumers, the online retailers might be able to accurately create, manage and satisfy the emerging feelings of consumers by providing the right products and services. This is because the emotional processing capabilities will give important effects on how consumers think and act.

Although all the hypothesized relationships of emotional intelligence, trust, perceived value and purchase intention and confirmation were supported, detail research in the future to examine the relationships among the constructs through other methods of studies is suggested for a better understanding of the consumers' behaviour. This should include gauging the consumers' willingness to make purchase based on social inference, and exploring the factors that will influence the consumers' emotional intelligence. This effort will expand the scope of the consumer studies by addressing the psychological dimensions of consumer purchasing behaviour.

\section{Acknowledgements}

The study was supported by grants from the Ministry of Higher Education Malaysia, under the Fundamental Research Grant Scheme (FRGS). The author also wants to acknowledge Research Management Institute, Universiti Teknologi MARA for the support in conducting the research.

\section{References}

1. Benbasat, I. and Wang, W. (2005), 'Trust in and adoption of online recommendation agents', Journal of the Association for Information Systems, 6(3), 72-101.

2. Bhattacherjee, A. (2001), 'Understanding information systems continuance: An expectation-confirmation model', MIS Quarterly, 25 (3), 351-370.

3. Chong, B., Yang, Z. and Wong, M. (2003, September) Asymmetrical impact of trustworthiness attributes on trust, perceived value and purchase intention: a conceptual framework for cross-cultural study on consumer perception of online auction. In Proceedings of the 5th international conference on Electronic commerce (pp. 213-219). ACM.

4. Dodds, WB, Monroe, KB. and Grewal, D. (1991), 'Effect of price, brand and store information on buyers' product evaluations', Journal of Marketing Research, 28 (3), 307319.

5. Dunn, J. (1990) Trust and political agency, in Trust: Making and breaking cooperative 
relations, Gambetta, D. (ed) Oxford: Blackwell, pp. 73-93.

6. Hassan, S., Zambri, S., Kasiran, MK., Mahli, MT., Abd Ghani, NF. and Muhammad, M. (2012) 'Conformance of Malaysia ecommerce blogs with quality content theories', Journal of Internet and e-Business, 2012, 1- 9.

7. Heffernan, T., O’Neill, G., Travaglione, T. and Droulers, M. (2008), 'Relationship marketing the impact of emotional intelligence and trust on bank performance', International Journal of Bank Marketing, 26 (3), 183-199.

8. Jøsang, A., \& Presti, SL. (2004), 'Analysing the relationship between risk and trust. In Trust Management (pp. 135-145). Springer Berlin Heidelberg.

9. Dodds, WB. and Monroe, KB. (1985), "The effect of brand and price information on subjective product evaluations', Advances in Consumer Research, 12(1), 85-90.

10. Gefen, D., Karahanna, E. and Straub, DW. (2003), 'Trust and TAM in online shopping: an integrated model, MIS quarterly, 51-90.

11. Kidwell, B., Hardesty, D. M., and Childers, T. L. (2008), 'Consumer emotional intelligence: Conceptualization, measurement, and the prediction of consumer decision making, Journal of Consumer Research, 35 (1), 154-166.

12. Kwek, CL., Tan, HP. \& Lau, TC. (2010), 'Investigating the shopping orientations on online purchase intention in the e-commerce environment: A Malaysian study', Journal of Internet Banking and Commerce, 15(2), 1-22.

13. Morgan, RM. and Hunt, SD. (1994), 'The commitment-trust theory of relationship marketing. Journal of Marketing, 20-38.

14. O'Malley, L. and Tynan, C. (1997), 'A reappraisal of the relationship marketing constructs of commitment and trust. New and evolving paradigms: The emerging future of marketing, Three American Marketing Association Special Conferences, Dublin, 486-503.

15. Salisbury, WD., Pearson, RA., Person, A. and Miller, D. W. (2001), 'Perceived security and World Wide Web purchase intention', Industrial Management and Data Systems, 101(4), 165-176.

16. Sirdeshmukh, D., Singh, J. and Sabol, B. (2002), 'Consumer trust, value and loyalty in relational exchanges', Journal of Marketing, 15-37.

17. Sonja, GK. (2002), 'The role of consumers' trust in online-shopping. Journal of Business Ethics. 39 (1/2), 43-50.

18. Tan, H. and Guo. J. (2005), 'Some methods to depress the risk of the online transactions', ICEC"05, August 15-17, 2005, Xi"an, China.

19. Thaler, R. (1985), 'Mental accounting and consumer choice', Marketing Science, 4(3), 199-214. 